\title{
Biosynthesis of Tetrahydrobiopterin in Man
}

\author{
H.-Ch. Curtils, D. Heintel, S. Ghisla ${ }^{1}$, Th. Kuster, W. Leimbacher and A. Niederwieser \\ Ditision of Clinical Chemistry. Depatment of Pediatrics. Unitersity of Zurich, Switzerland \\ ${ }^{1}$ Department of Biology, Unitersity of Constance, POB 5560, D-7750 Constance, FRG
}

\begin{abstract}
The biosynthesis of tetrahydrobiopterin $\left(\mathrm{BH}_{4}\right)$ from dihydroneopterin triphosphate $\left(\mathrm{NH}_{2} \mathrm{P}_{3}\right)$ was studied in human liver extract. The phosphate-eliminating enzyme (PEE) was purified $\sim 750$-fold. The conversion of $\mathrm{NH}_{2} \mathrm{P}_{3}$ to $\mathrm{BH}_{4}$ was catalyzed by this enzyme in the presence of partially purified sepiapterin reductase, $\mathrm{M}_{2}{ }^{2-}$ and NADPH. The PEE is heat stable when heated at $80^{\circ} \mathrm{C}$ for $5 \mathrm{~min}$. It has a molecular weight of 63000 daltons. One possible intermediate 6-(1'-hydroxy-2'-oxopropyl) 5,6,7,8-tetrahydropterin(2'-oxo-tetrahydropterin) was formed upon incubation of $\mathrm{BH}_{4}$ in the presence of sepiapterin reductase and NADP ${ }^{+}$at $\mathrm{pH}^{9} .0$. Reduction of this compound with $\mathrm{NaBD}_{4}$ yielded monodeutero threo and erythro- $\mathrm{BH}_{4}$, the deuterium uas incorporated at the 2' position. This and the UV spectra were consistent with a $2^{2}$-oxo-tetrahydropterin structure. Dihydrofolate reductase (DHFR) catalyzed the reduction of $\mathrm{BH}_{2}$ to $\mathrm{BH}_{4}$ and was found to be specific for the pro- $R$-NADPH side. The sepiapterin reductase catalyzed the transfer of the pro- $S$ hydrogen of NADPH during the reduction of sepiapterin to $\mathrm{BH}_{2}$. In the presence of crude liver extracts the conversion of $\mathrm{NH}_{2} \mathrm{P}_{3}$ to $\mathrm{BH}_{4}$ requires NADPH. Two deuterium atoms were incorporated from $\left(4 S_{-}{ }^{2} \mathrm{H} / \mathrm{NADHP}\right.$ in the $1^{\prime}$ and $2^{\prime}$ position of the $\mathrm{BH}_{4}$ side chain. Incorporation of one hydrogen from the solvent was found at position $\mathrm{C}(6)$. These results are consistent with the occurrence of an intramolecular redox exchange between the pteridine nucleus and the side chain and formation of 6-pyruvoyl-5,6,7,8-tetrahydropterin(tetrahydro-1 ' -2 'dioxopterin) as intermediate.
\end{abstract}

Despite the numerous studies carried out on tetrahydrobiopterin $\left(\mathrm{BH}_{4}\right)$ biosynthesis in mammals, several controversial aspects still have to be clarified (Levine et al.. 1983a: Ghisla et al. 1984). $\mathrm{BH}_{4}$ is a cofactor for phenylalanine, tryptophan and tyrosine hydroxylases. and it has been suggested that it also plays an important role in the regulation of the synthesis of biogenic amine neurotransmitters (Levine et al.. 1983b). Errors in $\mathrm{BH}_{4}$ biosynthesis and metabolism have been extensively studied in the rare childhood disease $\mathrm{BH}_{4}$-deficient hyperphenylalaninaemia. alternatively referred to as atypical phenylketonuria (Niederwieser et al.. 1982), as well as in certain neurological and psychiatric disorders (Curtius et al., 1982, 1983). The urinary excretion of neopterin (a metabolite of an intermediate in $\mathrm{BH}_{4}$ biosynthesis) has been shown to be elevated in certain diseases where there is an alteration in the status of the immune system (Wachter et al.. 1983). A complete understanding of the enzymatic steps in the $\mathrm{BH}_{4}$ biosynthesis in man is therefore of great importance.

The first reaction in mammalian $\mathrm{BH}_{4}$ biosynthesis involves the conversion of GTP to dihydroneopterin triphosphate $\left(\mathrm{NH}_{2} \mathrm{P}_{3}\right)$ by a single enzyme, GTP cyclohydrolase 1. This has been reported in nonmammalians by Fan and Brown (1976) in Drosophila and by our group in humans (Blau and Niederwieser. 1983). We developed an enzyme assay for GTP cyclohydrolase I in human liver biopsies and lymphocytes and reported the first patient with GTP cyclohydrolase deficiency (Niederwieser et al., 1984a). While the conversion of GTP to $\mathrm{NH}_{2} \mathrm{P}_{3}$ is catalyzed by a single enzyme in mammals. the further transformation of $\mathrm{NH}_{2} \mathrm{P}_{3}$ to $\mathrm{BH}_{4}$ is likely to involve several enzymes. It should be pointed out that up to now in the biosynthesis of $\mathrm{BH}_{4}$. only the structures of $\mathrm{GTP}, \mathrm{NH}_{2} \mathrm{P}_{3}$ and $\mathrm{BH}_{4}$ have been established beyond doubt. as shown in Figure 1. Current discussions and controversies deal mainly with the steps leading from $\mathrm{NH}_{2} \mathrm{P}_{3}$ to $\mathrm{BH}_{4}$.

Tanaka et al. (1981) reported that in chicken kidney. $\mathrm{NH}_{2} \mathrm{P}_{3}$ is converted through some intermediate " $x$ " to L-sepiapterin by a heat stable. magnesiun-dependent "fraction $A_{2}$ " It was suggested that " $x$ " was converted to

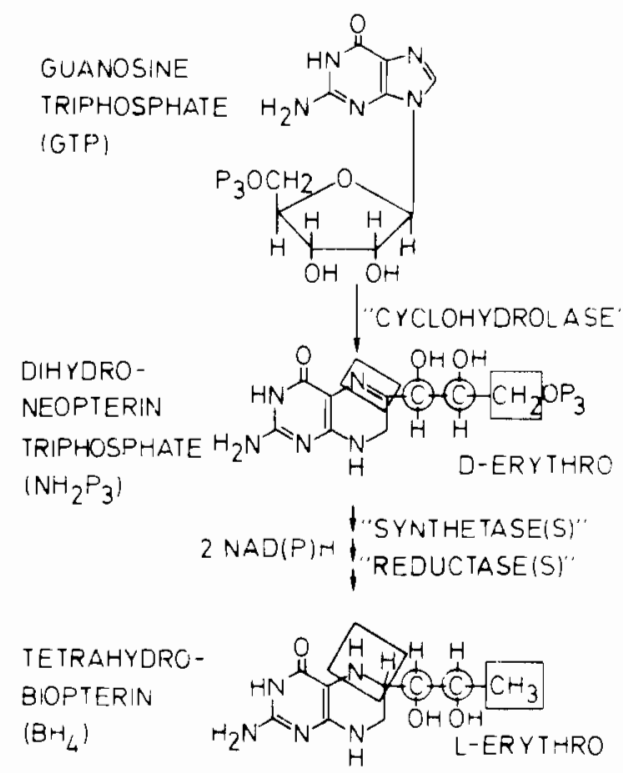

Figure 1 Biosvithesis of tet rahydrobiopterin from guanosine triphosphate. Note that only the structure of the molecules shown have been established beyond doubt. The parts of the molecules of $\mathrm{NH}_{2} \mathrm{P}_{3}$ which are subjeced to reduction are denoted by squares. those which undergo inversion by circles 
sepiapterin by the heat labile "fraction $A_{1}$ " which was reported to be NADPH-dependent, and that " $x$ " was a diketo-dihydropterin.

Regarding the potential of NADPH dependency of the sepiapterin formation from $\mathrm{NH}_{2} \mathrm{P}_{3}$, reported by some authors, it is puzzling that NADPH should be considered necessary since there is no net difference in the redox balance between $\mathrm{NH}_{2} \mathrm{P}_{3}$ and sepiapterin (Heintel et al., 1984). Recently, however, we showed that NADPH is not necessary in human and vertebrates for sepiapterin formation. $\mathrm{NH}_{2} \mathrm{P}_{3}$ was shown to be converted to sepiapterin without addition of NADPH as well as under conditions that ensured the destruction of endogenous, free NADPH (Heintel et al., 1984). Our results have also indicated that sepiapterin may not be an intermediate on the pathway leading to $\mathrm{BH}_{4}$ biosynthesis under normal in vivo conditions.

Duch et al. (1983) demonstrated the formation of $\mathrm{BH}_{4}$ in the presence of sufficient methotrexate to inhibit dihydrofolate reductase (DHFR) (EC 1.6.99.7) completely. This implied that sepiapterin is not on the biosynthetic pathway. This was also confirmed by Milstien and Kaufman (1983) and ourselves (Heintel et al., 1984). Together with the groups of Kaufman, Nichol and Brown, we suggested the occurrence of internal oxidoreduction reactions leading to tetrahydropterins without the need of NADPH (Heintel et al., 1984; Levine et al., 1983a). This process appears to be thermodynamically feasible (Ghisla et al., 1984).

A comparison of the chemical structures of $\mathrm{NH}_{2} \mathrm{P}_{3}$ and $\mathrm{BH}_{4}$ reveals that three distinct chemical transformations are required for their interconversion (see Figure 1): (a) elimination, (b) inversion, (c) reduction.

(a) Elimination: The elimination of a leaving group such as (tri)phosphate is a facile chemical reaction requiring a base which catalyzes the abstraction of the $\mathrm{C}\left(2^{\prime}\right)-\mathrm{H}$ as a proton. Several enzymes catalyzing phosphate elimination reactions are known, and the requirement for $\mathrm{Mg}^{2+}$ in reactions involving organic phosphates has been documented. During the reaction one proton from the solvent is introduced in the 3 position. However, a proton shift occurring at an active site shielded from $\mathrm{H}^{+}$exchange with solvent has also been proposed. This is shown in Figure 2. Whether, as in our case, such a shift occurs or not can be verified experimentally. Conservation of the $1^{\prime}$ or of the $2^{\prime}$ hydrogens in the $3^{\prime}-\mathrm{CH}_{3}$ of $\mathrm{BH}_{4}$ would be consistent with such hypothesis. Conversely, incorporation of (labeled) solvent hydrogen at $\mathrm{C}\left(3^{\prime}\right)$ would clearly exclude this type of mechanism. A possible enzyme catalyzing this conversion has been proposed by Tanaka et al. (1981), and is referred to as "fraction $\mathrm{A}_{2}$ " which has been shown to require $\mathrm{Mg}^{2+}$ for activity.

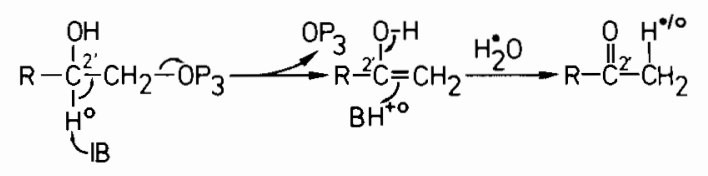

Figure 2. Elimination of triphosphate (b) Inversion: Two basically distinct types of biochemical inversions at chiral centers are known. One type of inversion can be induced directly by two enzyme active center bases and proceeds over a carbanionic transient. Alternatively, and as is likely to occur in our case, redox catalysis is involved and inversion could proceed via a planar $s p^{2}$ carbon center (Figure 3).

(c) Reduction: The difference in redox state between $\mathrm{NH}_{2} \mathrm{P}_{3}$ and $\mathrm{BH}_{4}$ is $4 e^{-}$. Reduction of the $\mathrm{C}(6)-\mathrm{N}(5)$ imine might, at first sight, be considered a normal hydrogenation reaction, such as those catalyzed by pyridine nucleotide or flavin enzymes. In the case when an intramolecular rearrangement reaction takes place, a keto-group in the $1^{\prime}$ position must be reduced (see Figure 10). The formal reduction at $\mathrm{C}\left(3^{\prime}\right)$, on the other hand, might involve a more complicated set of events, i.e. triphosphate elimination to form an enol, ketonization of the latter and finally reduction of the 2 '-keto group thus formed. The sequence of these events, elimination, intramolecular oxidoreduction reaction, inversion, and reduction of the keto-groups, is not established. Elimination can be an early event and has been proposed by Krivi and Brown (1979) to initiate the conversion. Milstien and Kaufman (1983), on the other hand, proposed that the sequence starts with the internal redox reaction.

Concerning biosynthesis, the following questions are still unclear:

(1) How is L-biopterin formed from D-neopterin with inversion of two chiral centers at $1^{\prime}$ and $2^{\prime}$ ? (see Figure 1).

(2) Are quinonoid intermediates or dihydropteridine reductase (DHPR) involved in the biosynthesis?

(3) Is the tetrahydro form of the pterin nucleus formed by an intramolecular redox rearrangement?

(4) What is the mechanism of the reduction steps? Does direct transfer of NADPH hydride occur? If yes, from which $(R$ or $S$ ) side?

(5) What is the role of sepiapterin reductase in the biosynthesis of $\mathrm{BH}_{4}$. Can it be confirmed that folate reductase is not involved?

To clarify these questions we investigated the biosynthesis with stereospecific deuterium labeled pyridine nucleotides.

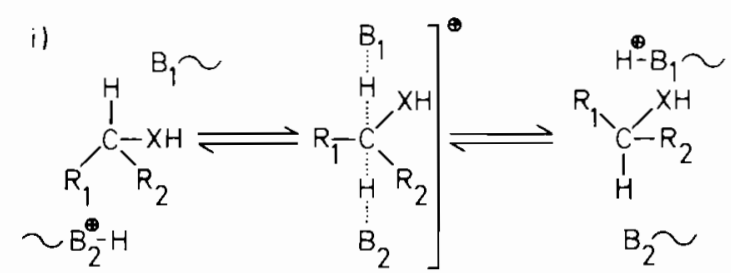

ii)

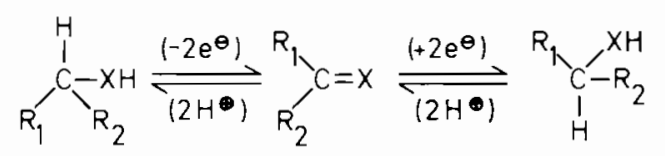

Figure 3 Biochemical mechanisms of inversion at chiral centers. (i) Inversion over a carbanionic intermediate; (ii) inversion via a planar $s p^{2}$ carbon center 


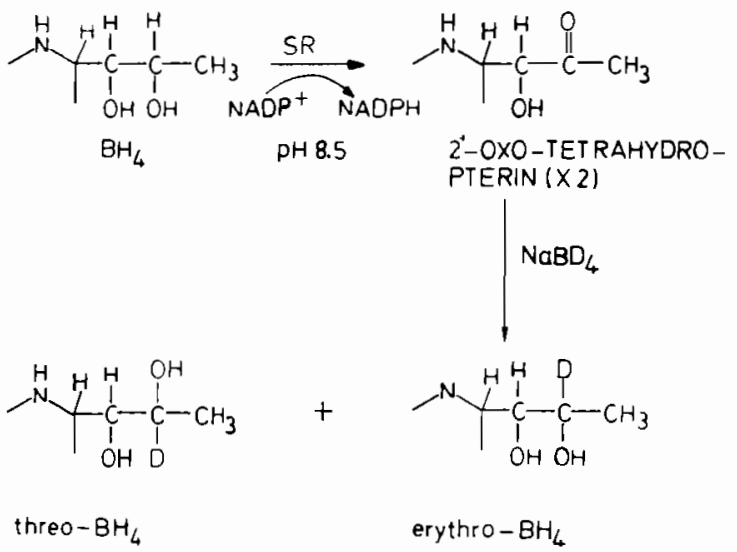

Figure 4 Reverse reaction of $\mathrm{BH}_{4}$ to $\mathrm{X} 2$ with sepiapterin reductase. The reaction mixture contained (final concentrations) in a total volume of $2 \mathrm{ml}, R-\mathrm{BH}_{4}\left(0.08 \mathrm{mmol}^{-1}\right)$, $\mathrm{NADP}^{+}\left(0.4 \mathrm{mmol}^{-1}\right), 60 \mathrm{mU}$ human sepiapterin reductase after purification on AcA 44 in 0.2 moll $^{-1}$ Tris $-\mathrm{HCl} \mathrm{pH} 9.0$. After $30 \mathrm{~min}$ at $25^{\circ} \mathrm{C}$, the mixture was acidified to $\mathrm{pH} 7.0$ and the protein separated over Sephadex G 25. The column was equilibrated in degassed $\mathrm{H}_{2} \mathrm{O}$ which contained DTE $\left(1 \mathrm{mmoll}^{-1}\right)$. The fractions which contained the $\mathrm{BH}_{4}$ and $\mathrm{X} 2$ were lyophilized. Afterwards X2 was isolated by HPLC (system described by Niederwieser et al., 1984b). Reduction of the isolated $\mathrm{X} 2$ was performed with $\mathrm{NaB}^{2} \mathrm{H}_{4}$ for $1 \mathrm{~min}$ at $\mathrm{pH}$ $\sim 8.0$ followed by adjustment to $\mathrm{pH} \sim 1$ with $\mathrm{HCl}$. The produced erythro- $\mathrm{BH}_{4}$ was purified for $\mathrm{GC}-\mathrm{MS}$ analysis

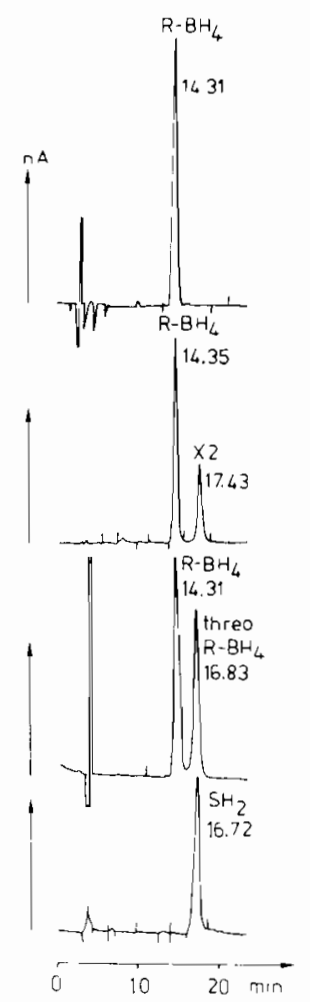

Figure 5 HPLC chromatography of tetrahydropterins with EC-detection. HPLC conditions as described elsewhere (Niederwieser et al., 1984), except that the eluent contained $5 \%$ methanol
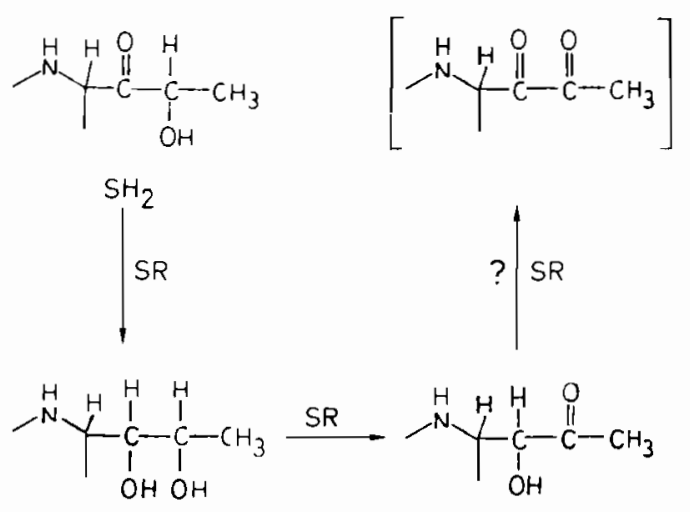

$\mathrm{BH}_{4}$

$\times 2$

Figure 6 Reactions of sepiapterin reductase

sepiapterin or dihydrobiopterin using extracts from human liver, purified sepiapterin reductase from human liver, rat erythrocytes and dihydrofolate reductase (Curtius et al., 1985). The incorporation of hydrogen in tetrahydrobiopterin was studied in either ${ }^{2} \mathrm{H}_{2} \mathrm{O}$ or $\mathrm{H}_{2} \mathrm{O}$ using deuterated $\left(R\right.$ - or $\left.S-{ }^{2} \mathrm{H}\right) \mathrm{NADH}$ and deuterated $(R-$ or $\left.S-{ }^{2} \mathrm{H}\right) \mathrm{NADPH}$. In NADPH-dependent enzyme reactions, the transfer of a hydride ion is stereospecific. Either the pro- $R$ or pro- $S$ hydride is transferred to the substrate (Figure 7).

\section{Dihydrofolate reductase ( $D H F R$ )}

In the formation of tetrahydrobiopterin from dihydrobiopterin in the presence of dihydrofolate reductase (DHFR), the pro- $R$ hydrogen of NADPH was transferred to the $C(6)$ position of the ring moiety of $\mathrm{BH}_{4}$. Therefore DHFR is specific for the pro- $R$ NADPH hydrogen (Figure 8).

Sepiapterin reductase

Sepiapterin reductase catalyzed the transfer of the pro-S hydrogen of NADPH during the reduction of sepiapterin at the side chain position $\mathrm{C}\left(1^{\prime}\right)$ to yield dihydrobiopterin (Figure 9).

Conversion of $\mathrm{NH}_{2} \mathrm{P}_{3}$ to $\mathrm{BH}_{4}$

During the conversion of $\mathrm{NH}_{2} \mathrm{P}_{3}$ to $\mathrm{BH}_{4}$ in the presence of human liver extract, arsenite to inhibit the $\mathrm{H} / \mathrm{D}$ exchange of NADPH with solvent (see below), NADPH and ${ }^{2} \mathrm{H}_{2} \mathrm{O}$, one deuterium was incorporated in the 6position of the ring. This is consistent with an intramolecular oxidoreduction reaction which is envisaged to occur via tautomerization in the $\mathrm{C}(6)$ position of the ring moiety and the $\mathrm{C}\left(1^{\prime}\right)$, as shown in Figure 10.<smiles>[R]N1C=C[C@H]([2H])C(C(N)=O)=C1</smiles>

(4R-D)NAD(P)H<smiles>[R]N1C=C[C@H]([2H])C(C(N)=O)=C1</smiles>

(4S-D) NAD(P)H
Figure 7 Transfer of either the pro- $R$ or pro-S hydride in NADPH-dependent enzyme reactions 


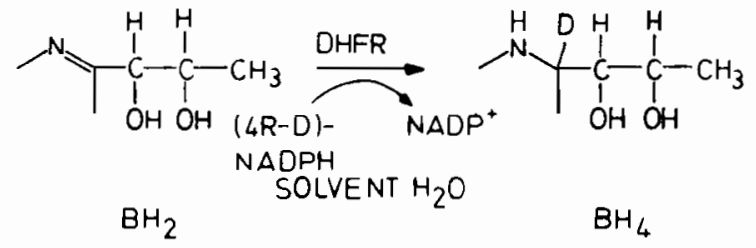

Figure 8 Hydrogen transfer from $\left(4 R-{ }^{2} \mathrm{H}\right) \mathrm{NADPH}$ by dihydrofolate reductase (substrate $\mathrm{BH}_{2}$, product $\mathrm{BH}_{4}$ )

During the conversion of $\mathrm{NH}_{2} \mathrm{P}_{3}$ to $\mathrm{BH}_{4}$ with crude extract from human liver and deuterated $\left(R-\right.$ or $\left.S-{ }^{2} \mathrm{H}\right)$ $\mathrm{NADPH}$ in $\mathrm{H}_{2} \mathrm{O}$, two deuterium atoms were incorporated in the $1^{\prime}$ and $2^{\prime}$ positions, respectively, from the $S$ side of deuterated NADPH. This could only be observed after inhibition of diaphorases which were present in the extract. The flavoprotein $\alpha$-lipoyl dehydrogenase, a diaphorase present in liver tissue, can catalyze a hydrogen exchange between NADPH and $\mathrm{H}^{+}$of $\mathrm{H}_{2} \mathrm{O}$ (Ernster et al., 1965).

\section{CONCLUSIONS}

(1) DHFR has been shown to be specific for the pro- $R$ NADPH side in the reduction of $\mathrm{BH}_{2}$ to $\mathrm{BH}_{4}$. During the conversion of $\mathrm{NH}_{2} \mathrm{P}_{3}$ to $\mathrm{BH}_{4}$ with crude human liver extracts, no deuterium transfer to the ring moiety of $\mathrm{BH}_{4}$ was found from either deuterated ( $S$ or $R$ ) NADPH. This indicates that $\mathrm{DHFR}$ is not involved in the biosynthesis of $\mathrm{BH}_{4}$ from $\mathrm{NH}_{2} \mathrm{P}_{3}$ and that $\mathrm{BH}_{2}$ is not an intermediate, which is in accordance with the conclusions of others (Duch et al., 1983).

(2) Our finding of the incorporation of one deuterium from the solvent into position 6 is consistent with the occurrence of an intramolecular oxidoreduction (see Figure 10).

(3) Our results show that during the conversion of $\mathrm{NH}_{2} \mathrm{P}_{3}$ to $\mathrm{BH}_{4}$ with deuterated $\left(\mathrm{S}^{2} \mathrm{H}\right) \mathrm{NADPH}$ in $\mathrm{H}_{2} \mathrm{O}$, one deuterium atom is incorporated each at the $1^{\prime}$ and the 2 ' position of the side chain. This requires that during biosynthesis, the intermediates must carry a diketo side chain at $\mathrm{C}(6)$.

(4) The dehydrogenation of $\mathrm{BH}_{4}$ by sepiapterin reductase to form 2 -oxo-tetrahydropterin indicates that the reverse reaction can also be catalyzed by this enzyme and that sepiapterin reductase could indeed take place in the reduction of the $1^{\prime}$ and the $2^{\prime}$ keto functions.

(5) The PEE appears to be involved in the elimination of phosphate. The exact locus at which

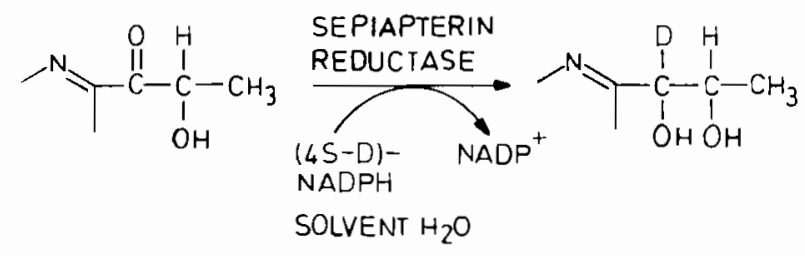

SEPIAPTERIN

$\mathrm{BH}_{2}$

Figure 9 Hydrogen transfer from $\left(4 S-{ }^{2} \mathrm{H}\right) \mathrm{NADPH}$ by sepiapterin reductase from rat erythrocytes (substrate sepiapterin, product $\mathrm{BH}_{2}$ )

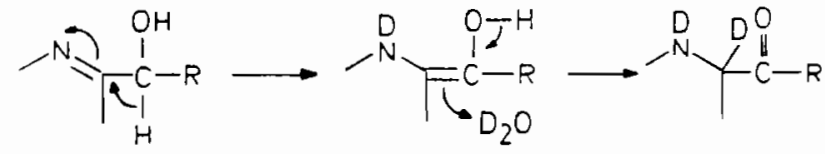

Figure 10 Intramolecular oxidoreduction reaction leading to tetrahydropterins without the need of NADPH

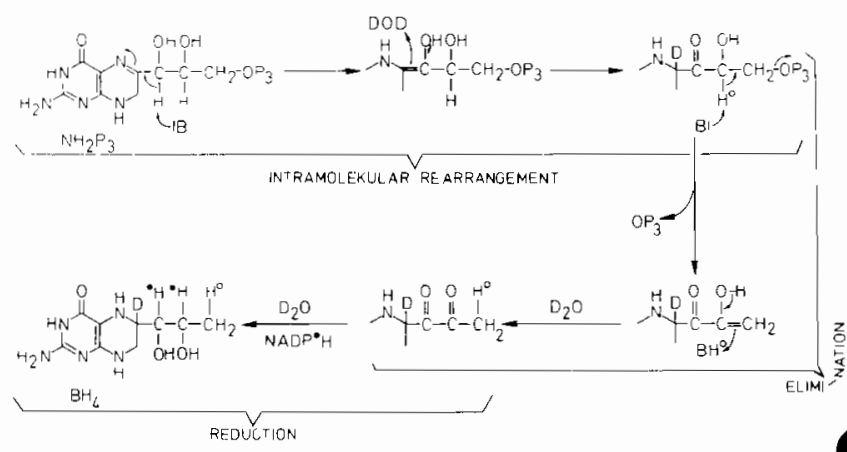

Figure 11 Possible pathway of $\mathrm{BH}_{4}$ biosynthesis including recent $\mathrm{GC}-\mathrm{MS}$ results of deuterated NADPH and $\mathrm{D}_{2} \mathrm{O}$ studies

elimination occurs in the sequence in Figure 11 cannot be determined by the present experiments.

From these results it can be calculated that the metabolic scheme of Figure 11 may be the most likely.

We thank Mr U. Redweik, Mr W. Staudenmann and Ms M Sappelt for skilful technical assistance, and Dr B. Zagalak and Dr R. A. Levine (NIH, Bethesda, MD, USA) for valuable discussions. We thank Prof Dr H. Simon (Technical University of Munich, FRG) for a sample of $\left(4 S-{ }^{2} \mathrm{H}\right) \mathrm{NADH}$ and for valuable discussions. This work was supported by the Swiss National Science Foundation, project no. 3'266-0.82.

\section{References}

Blau, N. and Niederwieser, A. Guanosine triphosphate cyclohydrolase I assay in human and rat liver using highperformance liquid chromatography of neopterin phosphates and guanine nucleotides. Analvt. Biochem. 128 (1983) 446-452

Curtius, H.-Ch., Müldner, H. and Niederwieser, A. Tetrahydrobiopterin: Efficacy in endogenous depression and Parkinson's disease. J. Neural. Transmission 55 (1982) 301-308

Curtius, H.-Ch., Niederwieser, A., Levine, R. A., Lovenberg, W., Woggon, B. and Angst, J. Successful treatment of depression with tetrahydrobiopterin. Lancel I (1983) $657-658$

Curtius, H.-Ch., Heintel, D., Ghisla, S., Kuster, Th., Leimbacher, W. and Niederwieser, A. Tetrahydrobiopterin biosynthesis. Studies with specifically labelled $\left({ }^{2} \mathrm{H}\right) \mathrm{NAD}(\mathrm{P}) \mathrm{H}$ and of enzymes involved. Eur.J. Biochem. 148 (1985) (in press)

Duch, D. S., Lee, C.-L., Edelstein, M. P. and Nichol, C. A. Biosynthesis of tetrahydrobiopterin in the presence of dihydrofolate reductase inhibitors. Molec. Pharmacol. 24 (1983) 103-108

Ernster, L., Hoberman, H. D., Howard, R. L., King, T. E., Lee, C.-P., Mackler, B. and Sottocasa, G. Stereospecificity of certain soluble and particulate preparations of mitochondrial reduced nicotinamide-adenine dinucleotide 
dehydrogenase from beef heart. Nature. Lond. 207 (1965) 940-941

Fan, C. L. and Brown, G. M. Partial purification and properties of guanosine triphosphate cyclohydrolase from Drosophila melanogaster. Biochem. Genet. 14 (1976) 259-270

Ghisla, S., Curtius, H.-Ch. and Levine, R. A. Chemical considerations on the biosynthesis of tetrahydrobiopterin. In Pfleiderer, W., Wachter, H. and Curtius, H.-Ch. (eds.) Biochemical and Clinical Aspects of Pteridines, Vol. 3, De Gruyter, Berlin. 1984, pp. 35-52

Heintel, D., Ghisla, S., Curtius, H.-Ch., Niederwieser, A. and Levine, R. A. Biosynthesis of tetrahydrobiopterin: Possible involvement of tetrahydrobiopterin intermediates. Neurochem. Int. 1 (1984) 141-155

Krivi, G. G. and Brown, G. M. Purification and properties of the enzymes from Drosophila melanogaster that catalyze the synthesis of sepiapterin from dihydroneopterin triphosphate. Biochem. Genet. 17 (1979) 371-390

Levine, R. A., Heintel, D.. Leimbacher, W., Niederwieser, A., Curtius, H.-Ch. and Ghisla, S. Recent advances in tetrahydrobiopterin biosynthesis and the treatment of human disease. In Curtius, H.-Ch., Pfleiderer, W. and Wachter, H. (eds.) Biochemical and Clinical Aspects of Pteridines, Vol. 2, De Gruyter, Berlin, 1983a, pp. 325--337

Levine, R. A., Lovenberg, W., Curtius. H.-Ch. and Niederwieser, A. Speculation on the mechanism of therapeutic action of tetrahydrobiopterin in human disease. In Blair, J. A. (ed.) Chemistry and Biology of Pteridines, De Gruyter, Berlin, 1983b, pp. 833-837

Milstien, S. and Kaufman, S. Tetrahydro-sepiapterin is an intermediate in tetrahydrobiopterin biosynthesis, Biochem. Biophys. Res. Commun. 115 (1983) 888-893

Niederwieser, A., Blau, N., Wang, M., Joller, P., Atarés, M. and Cardesa-Garcia, J. GTP cyclohydrolase 1 deficiency, a new enzyme defect causing hyperphenylalaninemia with neopterin, biopterin, dopamine, and serotonin deficiencies and muscular hypotonia. Eur. J. Pediatr. 141 (1984a) 208-214
Niederwieser, A., Matasovic, A., Staudenmann, W., Wang, M. and Curtius, H.-Ch. Screening for tetrahydrobiopterin deficiency. In Wachter, H., Curtius, H.-Ch. and Pfleiderer, W. (eds.) Biochemical and Clinical Aspects of Pteridines, Vol. 1, De Gruyter, Berlin, 1982, pp. 293-306

Niederwieser, A., Staudenmann, W. and Wetzel, E. Highperformance liquid chromatography with column switching for the analysis of biogenic amine metabolites and pterins. $J$. Chromatogr. 290 (1984b) 237-246

Niederwieser, A., Ponzone, A. and Curtius, H.-Ch. Differential diagnosis of tetrahydrobiopterin deficiency. J. Inher. Metab. Dis. 8 Suppl. 1 (1985) 34-38

Smith, G. K. and Nichol, C. A. Studies on the biosynthesis of tetrahydrobiopterin in bovine adrenal medulla preparations. In Curtius, H.-Ch., Pfleiderer, W. and Wachter, H. (eds.) Biochemical and Clinical Aspects of Pteridines, Vol. 2, De Gruyter, Berlin, 1983, pp. 123-131

Smith, G. K. and Nichol, C. A. Two new tetrahydropterin intermediates in the adrenal medullary de novo biosynthesis of tetrahydrobiopterin. Biochem. Biophys. Res. Commun. 120 (1984) 761-766

Sueoka, T. and Katoh, S. Purification and characterization of sepiapterin reductase from rat erythrocytes. Biochim. Biophys. Acta 717 (1982) 265-271

Suzuki, A. and Goto, M. Isolation of D-erythro-neopterin $2^{\prime}: 3^{\prime}$-cyclic phosphate from Photobacterium phosphoreum. Biochim. Biophys. Acta 304 (1973) 222-224

Switchenko, A. C., Primus, J. P. and Brown, G. M. Intermediates in the enzymic synthesis of tetrahydrobiopterin in Drosophila melanogaster. Biochem. Biophys. Res. Commun. 120 (1984) 754-760

Tanaka, K., Akino, M., Hagi, Y., Doi, M. and Shiota, T. The enzymatic synthesis of sepiapterin by chicken kidney preparations. J. Biol. Chem. 256 (1981) 2963-2972

Wachter, H. et al. In Curtius, H.-Ch., Pfleiderer, W. and Wachter, H. (eds.) Biochemical and Clinical Aspects of Pteridines, Vol. 2, De Gruyter, Berlin, 1983 